\title{
ВЫБОРЫ ПРЕДСЕДАТЕЛЯ ЕВРОПЕЙСКОЙ КОМИССИИ: КАК ЭТО МОГЛО БЫТЬ И КАК ЭТО БЫЛО В 2019 ГОДУ
}

\begin{abstract}
Аннотация. В статье исследуется происхождение процедуры Spitzenkandidaten, нацеленной на продвижение кандидата от партий в Европейском парламенте на пост Председателя Европейской комиссии. Автор подтверждает гипотезу о перманентном дефиџите демократического контроля в деятельности Европейского союза фактом провала проиедуры на выборах в 2019 г. В статье выделены возможные причины этого провала - неподходящие кан-дидаты, несовершенство прочедуры, рыхльй состав Европарламента в качестве начальной гипотезы для политологов, которым предстоит дать развернутую оченку этой кампании.
\end{abstract}

Ключевые слова: прочесс Spitzenkandidaten, Европейский союз (EC), выборы, Европарламент (ЕП), европейские партии, Европейская комиссия (ЕК), выборы Председателя Европей-ской комиссии.

Избрание Урсулы фон дер Ляйнен в середине июля 2019 г. на пост главы Европейской комиссии послужило поводом обратить внимание на перипетии институционального развития Европейского союза, работающего в условиях перманентного дефицита демократического контроля и столь же перманентной борьбы институтов за свои полномочия. В настоящей статье речь идёт об идее, которую в течение 20 лет продвигает Европейский парламент. А именно, участие граждан в выборе главы ЕК - исполнительной власти ЕС. Промежуточным результатом борьбы ЕП за права избирателей стал «процесс Spitzenkandidaten»- процедура, в соответствии с которой европейские политические партии в преддверии европейских выборов назначают кандидатов на пост председателя ЕК, способных получить достаточную парламентскую поддержку.

ЕП впервые опробовал новую процедуру в 2014 г. и твёрдо был намерен применить её в 2019 г. Исследовательский вопрос статьи - происхождение процедуры и причины её провала на выборах 2019 г. Для этого выделим три возможные составные части этого провала: неподходящие кандидаты, несовершенство процедуры, несостоятельность ЕП.

\section{Кандидаты}

От Европейской народной партии (ЕНП) был избран её председатель Манфред Вебер, член ХСС Германии. На Хельсинкском конгрессе ЕНП 8 ноября 2018 г. он обошёл, набрав 79\% голосов делегатов, Александра Стубба, члена Национальной коалиции Финляндии, бывшего премьер-министра страны и в настоящее время вице-президента Европейского инвестиционного банка. Кандидатуру Вебера поддержала Ангела Меркель. Однако проблема была

\footnotetext{
(C) Кондратьева Наталия Борисовна - кандидат экономических наук, доцент, ведущий научный сотрудник Отдела исследований европейской интеграции, учёный секретарь Института Европы РАН; доцент НИУ «Высшая школа экономики»; заведующая базовой кафедрой европейских и интеграционных исследований Института мировых цивилизаций. Aдpec: 125009, Россия, Мос-ква, ул. Моховая, д. 11, стр. 3. E-mail: nkondratieva@ inbox.ru.
}

DOI: http://dx.doi.org/10.15211/vestnikieran420193843 
не в них, а в утрате Европейской народной партией своих позиций в ходе выборов в ЕП. Для поддержки кандидата необходимо было искать коалиции с социалистами и либералами.

На Лиссабонском конгрессе 8 декабря 2018 г. Партия европейских социалистов (ПЕС) одобрила в качестве своего кандидата первого вице-президента ЕК, ответственного за верховенство права, Франса Тиммерманса, члена Партии труда Нидерландов. Франс Тиммерманс был единственным кандидатом в гонке, после того как его конкурент зампредседателя ЕК по вопросам энергетики, словак Марош Шефчович снял свою кандидатуру (в 2019 г. став кан-дидатом в президенты Словакии). Напомним, что Франс Тиммерманс сыграл ведущую роль в ходе переговоров о соглашении ЕС с Турцией 2016 г. по сокращению потока мигрантов. На последней должности ответственного в ЕК за верховенство права, он нажил недругов в руководстве Польши, Венгрии, Румынии, Италии, Чехии. Его недавнее политическое предложение - введение минимальной заработной платы в каждом государстве-члене - также неприемлемо для стран ЦВЕ.

В ходе Мадридского партийного съезда 9 ноября 2018 г. Альянс либералов и Демократов за Европу выдвинул вместо одного лидера целую команду. 21 марта 2019 г. в Брюсселе АЛДЕ выделил среди них Маргрету Вестагер, члена Радикальной Венстре (Дания). Г-жа Вестагер провела последние пять лет в Комиссии Юнкера, возглавляя антимонопольные рассле-дования Европейского союза, которые закончились большими штрафами в адрес технологических гигантов Google и Apple. Такой председатель ЕК мог бы вызвать недовольство президента США Дональда Трампа.

Другие кандидаты от европейских партий не столь широко известны. Например, Альянс европейских консерваторов и реформистов выдвинул депутата от Чехии Яна Заградила, члена Гражданской демократической партии Чехии, в качестве кандидата на высокий пост в ноябре 2018 г. Кандидат от Европейской партии зелёных - немка 37 лет Ска Келлер, была из-брана на эту роль в ходе конгресса партии в Берлине 23-25 ноября 2018 г.

В целом о кандидатах можно сказать, что все они были слишком хороши, все зарекомендовали себя своей принципиальной позицией, и ни один не попытался создать коалицию, чтобы выйти в лидеры, а потому никто и не получил весомой поддержки ЕП.

\section{Происхождение механизма назначения}

Изначально Европейский парламент не играл никакой роли в назначении Председателя Европейской Комиссии. Маастрихтский договор (1992) впервые отвёл ему консультативную роль в этом процессе. ЕП также приобрёл право утверждать и отклонять состав Комиссии.В соответствии с Амстердамским договором (1997) ЕП получил полномочия утверждать кандидатуру Председателя ЕК. В то же время полномочия по выдвижению кандидата на этот высокий пост по-прежнему оставались в руках национальных правительств. До Ниццкого договора (2001) Председатель назначался с общего согласия правительств государствчленов, а после - формально квалифицированным большинством (на практике поиск консенсуса всё же был необходим). В результате, процесс назначения продолжал быть непрозрачным, точнее, был заложником «закулисного торга» между правительствами ${ }^{1}$.

Однако скромные полномочия не помешали ЕП в 1981 г. провести «символическое» голосование по кандидатуре на пост президента Комиссии ${ }^{2}$, а затем внедрить практику

\footnotetext{
${ }^{1}$ Roberto Baldoli, Stefan Gänzle and Michael Shackleton. Overthrowing Secrecy The Spitzenkandidaten experiment and a new chance for a European party system. CEPS Commentary, 04. 08.2014. URL: https://www.ceps.eu/wp-content/ up loads/2014/08/Overthrowing\%20Secrecy\%20-\%20Spitzenkandidaten\%20Experiment 0.pdf (дата обращения: 23.07. 2019).

${ }_{2}^{2}$ Martin Westlake. Chronicle of an Election Foretold: The Longer-Term Trends leading to the «Spitzenkandidaten» proНаучно-аналитический вестник ИЕ РАН, 2019, №4
} 
представления членам ЕП программы будущего Председателя.

С Лиссабонским договором (2007) соответствующие положения претерпели дальнейшие изменения. Основополагающие Договоры отныне требуют, чтобы Европейский совет квалифицированным большинством выдвинул кандидатуру Председателя ЕК, «принимая во внима-ние выборы в Европейский парламент» и «после проведения соответствующих консультаций», а также предусматривают, что предложенный кандидат должен быть «избран» Европейским парламентом большинством его членов (376 из 751 голосов) или 353 из 705, если считать без членов ЕП от Великобритании. В договорах также указано, что ЕП и Европейский совет «не-сут совместную ответственность» за отлаженность процесса, ведущего к выборам Председателя ЕК, в частности, должным образом учитывают необходимость соблюдения «географиче-ского и демографического разнообразия» ЕС и его государств-членов в этом процессе, а соответствующие консультации «должны быть посвящены истории кандидатов». Наконец, согласно требованиям Договоров, если ЕП не получит необходимое большинство, Европейский совет, действующий квалифицированным большинством, в течение одного месяца должен предложить нового кандидата, который будет избран ЕП, следуя той же процедуре.

Заметим, что в Лиссабонском договоре прямо не упоминается процесс, посредством которого европейские политические партии назначают «их» кандидатов, а затем Председательство переходит к политической партии, получившей наибольшее количество мест или, по крайней мере, способной собрать поддержку достаточного количества членов парламента. Та-ким образом, процесс, который стал известен как процесс Spitzenkandidaten (нем. яз.), и кото-рый мы два раза подряд наблюдали в ходе выборов Председателя ЕК, можно назвать творческим толкованием Договора, причём, как со стороны ЕП, так и со стороны ЕК.

Одно из официальных изданий ЕК указывает, что ведущие деятели ЕП и политические партии выдвинули идею о привлечении ведущих кандидатов ещё в конце 1990-х гг. ${ }^{1}$ История процесса Spitzenkandidaten стартует в 1997 г., когда Христианско-демократический союз Германии (ХДС) ухватился за идею выдвинуть топ кандидата на европейских выборах, который бы становился Председателем ЕК, если партия выиграет большинство.

Перед выборами 2014 г., в 2012 г. ЕП призвала европейские политические партии «выдвигать кандидатов на пост Председателя ЕК». При этом предполагалось, что избрание подразумевает выбор и, следовательно, множественность кандидатов, а не простое «одобрение» предложения Европейского совета. ЕП выражал надежду на то, что кандидатура в Председатели ЕК, выдвинутая европейской политической партией, получившей наибольшее количество мест в ЕП, будет рассмотрена первой, однако, не «обещал» председательство в ЕК побе-дившей партии.

Первое очевидное выдвижение кандидата от партии было сделано Европейской народной партией во время Варшавского конгресса 29-30 апреля 2009 г. Но заметим, вопервых, что этой кандидатурой был действующий Президент Комиссии, Жозе Мануэл Баррозу. Во-вто-рых, кандидатура была одобрена (16 сентября 2009 г.) Европейским парламентом главным образом голосами партии. В-третьих, голосование проходило на

cedure and the Election of Jean-Claude Juncker as European Commission President. LEQS paper №102/2016. P. 36. URL: http://www.lse.ac.uk/european-institute/Assets/Documents/LEQS-Discussion-Papers/LEQSPaper102.pdf (дата обращения: 23.07.2019).

${ }^{1}$ Building on the Spitzenkandidaten Model Bolstering Europe's Democratic Dimension. European Political Strategy Centre. Issue 1. 16.02.2018. P. 3. URL: https://ec.europa.eu/epsc/sites/epsc/files/epsc_-_road_to_sibiu_-_building_on_ the_spitzenkandidaten_model.pdf (дата обращения: 23.07.2019). 
безальтернативной основе. Как следствие, в 2012 г. Баррозу призвал другие европейские политические партии выдвинуть кандидатов на пост Председателя ЕК; в 2013 г. Комиссия выступила с соответствующей Рекомендацией.

В конце 2013 г. и начале 2014 г. пять европейских политических партий предложили своих кандидатов на пост Председателя ЕК. Ими были: Жан-Клод Юнкер (Европейская народная партия), Мартин Шульц (Партия европейских социалистов), Ги Верхофстадт (Альянс либералов и демократов), Ска Келлер и Жозе Бове (Европейский партия зелёных) и Алексис Ципрас (Европейские левые).

Источник ЕК пишет, что Парламент провёл предвыборную кампанию 2014 г. под лозунгом «на этот раз всё иначе»: голосуя на европейских выборах, граждане Евросоюза не только изберут парламент, но и также смогут повлиять на то, кто будет возглавлять исполнительную власть ЕС - Комиссию. Во время кампании ведущие кандидаты приняли участие в ряде телевизионных дебатов, давали интервью, участвовали в митингах и т. д.

Опыт был признан положительным. Но был ли он таковым на самом деле, ответим ниже.

\section{Что не так? Европейский парламент?}

Напомним, что на европейских выборах 2014 г. ЕНП получила в общей сложности 221 место $(29,43 \%$ голосов) и стала самой большой группой в ЕП. За ней следовала ПЕС с 191 местом (25,43\% голосов). Европейский совет 26-27 июня 2014 г. назначил Ж.-К. Юнкера кандидатом в Председатели ЕК квалифицированным большинством (Великобритания и Венгрия голосовали против). 15 июля 2014 г. ЕП избрал Ж.-К. Юнкера Председателем ЕК 422 голосами «за», 250 «против» и 47 воздержавшихся ${ }^{1} .1$ ноября 2014 г. он вступил в должность. Большинства достичь было несложно.

Майские европейские выборы 2019 г. сделали ЕП более раздробленным, что затрудняло принятие решений. ЕПП, к примеру, получила только 24\% мандатов. Результаты выборов были расценены аналитиками как фактор, который негативно повлияет на выбор руководителей основных институтов Европейского союза, в том числе Председателя ЕК. Основной вопрос был в том, состоятелен ли процесс Spitzenkandidaten, соответственно, укрепится ли влияния ЕП на Европейский совет. Политтехнологи говорят, что в новом ЕП для создания большинства нужна более широкая партийная коалиция, в которую должны быть включены помимо Европейской народной партии и Альянса социалистов с демократами также либералы и зелёные.

Не будем отрицать: Европейский парламент стремился создать подлинный конкурс на высшую руководящую должность. К этому же стремились и кандидаты. В резолюции от 7 февраля 2018 г. ЕП призвал европейские партии выдвигать своих кандидатов посредством «открытой, прозрачной и демократической конкуренции» (п. 10 Резолюции) ${ }^{2}$. Теледебаты (в частности, 15 мая 2019 г.) между кандидатами, представляющими шесть главных европейских политических партий, освещал канал Euronews.

Одержавший победу в рамках первого эксперимента в 2014 г. Председатель комиссии Ж.-К. Юнкер в 2017 г. поддержал процедуру, как и его предшественник Баррозу. «Если вы хотите укрепить европейскую демократию, тогда вы не можете повернуть вспять

\footnotetext{
${ }^{1}$ Tilindyte Laura. Election of the President of the European Commission Understanding the Spitzenkandidaten process. European Parliamentary Research Service. April 2019. P.4-5. URL: http://www.europarl.europa.eu/RegData/etudes/ BRIE/2018/630264/EPRS BRI(2018)630264 EN.pdf (дата обрашения: 23.07.2019).

${ }^{\frac{B}{2}}$ European Parliament decision of 7 Februarv 2018 on the revision of the Framework Agreement on relations between the European Parliament and the European Commission. URL: http://www.europarl.europa.eu/doceo/document/TA-82018-0030_EN.html?redirect (дата обращения: 23.07.2019).
} 
демократический прогресс выдвижения ведущих кандидатов - Spitzenkandidaten. Я хотел бы, чтобы опыт повторился», - заявил он 13 сентября 2017 г. ${ }^{1}$ Однако вряд ли можно считать, что процесс успешно закрепился. Ведь его конечным итогом стал выбор кандидатуры не из числа кандидатов.

Кандидатура на пост председателя Комиссии должна была быть предложена Европейским советом квалифицированным большинством. Евросовет много раз обсуждал вопрос на-значения на своих неофициальных и официальных заседаниях, начиная с февраля 2018 г., но ни одна из кандидатур от партий не нашла отклика в «элитах».

28 мая группа из шести национальных лидеров - представителей крупнейших политических групп в новом составе ЕП - была неофициально назначена Евросоветом для дальней-шего обсуждения. Их лица появились в СМИ в качестве потенциальных кандидатов на долж-ность. Несмотря на длительные переговоры, 20 июня на саммите соглашение не было достиг-нуто. Процедура провалилась.

30 июня - 2 июля 2019 г. было проведено специальное заседание Европейского совета. Кандидатура Урсулы фон дер Лейен была оглашена в числе предложений по другим выборным должностям.

После прений 16 июля Европейский парламент утвердил предлагаемое имя на посту Председателя ЕК. Кандидатура набрала 383/327 голосов.

Немка, родившаяся в Брюсселе, мать семерых детей, «зелёная», чиновник Бундесвера стала идеальным кандидатом для большинства, воплощением европейского образа жизни, европейских ценностей, европейской безопасности.

\section{Заключение}

Дальнейшая судьба процедуры Spitzenkandidaten, как и причины её фактического провала в 2019 г., требуют дальнейшего осмысления. По результатам актуального анализа провал демократической процедуры парадоксален. Во-первых, основной демократический институт, в условиях фрагментации своего состава, не смог достичь необходимого решения. Во-вторых, кандидаты от европейских партий в логике основной идеи процедуры (о честной конкуренции кандидатов) проявили принципиальность и не пошли на коалиции. Итог сохранение ба-ланса полномочий Европейского совета и Европейского парламента при выборе кандидатуры Президента ЕК.

\section{Список литературы}

Кавешников Н.Ю. Трансформация институциональной структуры Европейского союза. М., МГИМО, 2010.

Потемкина О.Ю. Европейский парламент 2019: подготовка к выборам. Современная Европа, №4, 2018. С. 35-46.

Стрежнева М.В. Институциональное развитие ЕС. Европейский Союз на пороге XXI века. Выбор стратегии развития. Под ред. Борко Ю.А., Буториной О.В. М., 2000. С. 237-270.

Кондратьева Н.Б. Новый старт для Европы или повторение пройденного. Металлы Евразии, №2, 2015. С. 58-61.

\section{References}

Kaveshnikov N.Yu. Transformaciya institucional'noj struktury Evropejskogo soyuza. M.,

\footnotetext{
${ }^{1}$ European Commission - Speech PRESIDENT JEAN-CLAUDE JUNCKER'S State of the Union Address 2017. Brussels, 13.09.2017. URL: http://europa.eu/rapid/press-release_SPEECH-17-3165_en.htm (дата обращения: 23.07.2019). Научно-аналитический вестник ИЕ РАН, 2019, №4
} 
MGIMO, 2010.

Potemkina O.Y. Evropejskij parlament 2019: podgotovka k vyboram. Sovremennaya Evropa. №4, 2018. S. 35-46.

Strezhneva M.V. Institucional'noe razvitie ES. - Evropejskij Soyuz na poroge XXI veka. Vybor strategii razvitiya. Pod red. Borko Yu.A., Butorinoj O.V. M, 2000. S. 237-270.

Kondrat'eva N.B. Novyj start dlya Evropy ili povtorenie projdennogo. Metally Evrazii, №2, 2015. S. 58-61.

Roberto Baldoli, Stefan Gänzle and Michael Shackleton. Overthrowing Secrecy the Spitzenkandidaten experiment and a new chance for a European party system. CEPS Commentary, 04.08.2014. URL: $\quad$ https://www.ceps.eu/wp-content/uploads/2014/08/Overthrowing\%20Secrecy\%20-\%20Spit zenkan didaten\%20Experiment_0.pdf.

Martin Westlake. Chronicle of an Election Foretold: The Longer-Term Trends leading to the «Spitzenkandidaten» procedure and the Election of Jean-Claude Juncker as European Commission President. LEQS paper №102/2016. P. 36. URL: http://www.lse.ac.uk/european-institute/Assets/ Documents/LEQS-Discussion-Papers/LEQSPaper102.pdf.

Building on the Spitzenkandidaten Model Bolstering Europe's Democratic Dimension. European Political Strategy Centre. Issue 1. 16.02.2018. P. 3. URL: https://ec.europa.eu/epsc/sites/epsc/ files/epsc__road to sibiu__building_on the spitzenkandidaten_model.pdf.

Laura Tilindyte. Election of the President of the European Commission Understanding the Spitzenkandidaten process. European Parliamentary Research Service. April 2019. P. 4-5. URL: http:// www.europarl.europa.eu/RegData/etudes/BRIE/2018/630264/EPRS_BRI(2018)630264_EN.pdf.

European Parliament decision of 7 February 2018 on the revision of the Framework Agreement on relations between the European Parliament and the European Commission. URL: http://www. europarl.europa.eu/doceo/document/TA-8-2018-0030_EN.html?redirect.

European Commission - Speech PRESIDENT JEAN-CLAUDE JUNCKER'S State of the Union Address 2017. Brussels, 13.09.2017. URL: http://europa.eu/rapid/press-release SPEECH-173165_en.htm.

\section{Election of Commission President: how it could be and how it was in 2019}

Author. Natalya Kondratyeva, Candidate of Sciences (Economics), Leading Researcher, Department of European Integration Studies, Academic Secretary, Institute of Europe, Russian Academy of Sciences; Associate Professor, National Research University - Higher School of Economics; Head of the Specialised Department of European and Integration Studies, Institute of World Civilizations. Address: 11-3, Mokhovaya str., Moscow, Russia, 125009. E-mail: nkondratieva@inbox.ru.

Abstract. The paper investigates the origin of the Spitzenkandidat Procedure, which is aimed at promoting the candidate of the European Parliament parties to the post of Chairman of the European Commission. The author confirms the hypothesis of a permanent deficit of the democratic control in the activities of the European Union by the fact of the failure of the Spitzenkandidat procedure in 2019. The paper highlights the possible reasons for this failure - unsuitable candidates, imperfection of the procedure, loose composition of the European Parliament - as an initial hypothesis for political scientists who will give a detailed assessment of this campaign.

Key words: Spitzenkandidat Process, European Union, elections, European Parliament, European parties, European Commission, election of the President of the European Commission

DOI: http://dx.doi.org/10.15211/vestnikieran420193843 